\title{
Simplified Micro-Strip Wearable Antenna for Wireless Application
}

\author{
T. Shakeel* and P. Mohan kumar
}

School of Electronics and Electrical Engineering, Lovely Professional University, Phagwara, Punjab-144411, India; shakeel246@gmail.com, mohan.15771@lpu.co.in

\begin{abstract}
In this paper basic micro-strip patch antenna used for applications mainly in wireless domain is presented in this paper. The resonant frequency of antenna is around $5 \mathrm{GHz}$, which is basically used for WLAN application. The design of antenna is done using Polystyrene substrate and copper as conducting material. Antenna parameters like return loss, band-width, gain and radiations patterns and VSWR are studied from this design, moreover design of antenna is planar type and can be flexible for usage.
\end{abstract}

Keywords: Micro-strip patch antenna, Return loss, Directivity, Voltage standing Wave Graph (VSWR), Wearable antennas

\section{Introduction}

Nowadays, micro-strip patch antennas are mostly used in applications where the space is limited. These types of antennas are mostly used in satellite communications, GPS, mobile, missile systems and in military applications. These antennas are preferred due to advantages like low profile, ease of manufacturing, very less fabrication cost, they are efficient radiators and easy to integrate with complex microwave circuits, However, there are disadvantages like low bandwidth, extra radiations from its feeds and junctions and surface wave radiations. Different bandwidth enhancement techniques also being introduced

Antenna described in this Polystyrene is used for WLAN application. WLAN is wireless local area network which is being used to create a wireless network using multiple devices with in limited range of areas like home, offices and close spaced buildings.

In this paper single layer antenna is designed, structure of antenna is shown in fig.

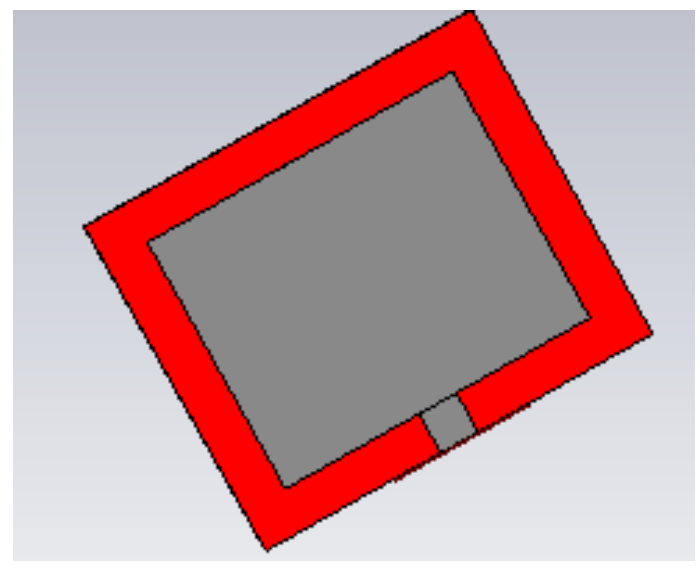

Figure 1. Structure of antenna..

The complete device consist of 3 components, rectangular patch which is made of copper is used as conducting material, ground plane and substrate material.. There are different feeding techniques for microstrip patch antenna, techniques are like direct feed, inset feed, probe feed, coupled feed and etc, each tecniques 
has its own pros and cons, but for simplicity direct feeding techniues is used in this design.

Nowadays due advancement in technology, humans are showing more interest in devices which gives much flexibility and uses less space, applications 月 of these type wearble antennas can be used for military applications, hospitals for transmission of different health parameters of patients to doctors and etc. The designing of antennas have become more easier with development of more advance simulators for computer Aided designing these days, simulators like HFSS, CST, Ie3D and etc. the antenna presented in this paper is designed using CST microwave studio simulator.

\section{Designing}

To design a microstrip patch antenna, resonant frequency need to known and type of material used as substrate is to be known depending on the application of usage. Substrate used in this design is flexible Polystyrene substrate with dielectric constant of 2.3. The dimensions of antenna are calculated using the equations stated below

- Width of patch

$$
W=\frac{C_{0}}{2 f_{r}} \sqrt{\frac{2}{\varepsilon_{r}+1}}
$$

- Effective dielectric constant $\left(\varepsilon_{r \in f f}\right)$ :

$$
\varepsilon_{r e f f}=\frac{\varepsilon_{r}+1}{2}+\frac{\varepsilon_{r}-1}{2}\left[1+12 \frac{h}{W}\right]^{-1 / 2}
$$

- $\quad$ Length (L):

$$
\frac{\Delta L}{h}=0.412 \frac{\left(\varepsilon_{\text {reff }}+0.3\right)\left(\frac{W}{h}+0.264\right)}{\left(\varepsilon_{\text {reff }}-0.258\right)\left(\frac{W}{h}+0.8\right)}
$$

$\Delta \mathrm{L}=$ change is electrical length of radiating patch due to fringing effect.

The Actual length $\mathrm{L}$ is given as

$$
L=\frac{C_{0}}{2 f_{r} \sqrt{\varepsilon_{r e f f}}}-2 \Delta L
$$

- Length $\left(\mathrm{L}_{\mathrm{g}}\right)$ and width $\left(\left(\mathrm{W}_{1}(\mathrm{~g})\right)\right.$ of ground plane:

$$
L_{g}=6 h+L
$$

$\mathrm{W}_{\mathrm{g}}=6 \mathrm{~h}+\mathrm{W}$

substrate dimensions like width and length will be same as dimension of ground plane.

The dielectric constant of material is found using bench setup consisting different microwave devices, the feeding technique used in this design is simple directfeed, with maintaining impedance of $50 \mathrm{ohm}$.

Table 1. Different dimension of antenna

\begin{tabular}{lc}
\hline Height of substrate & $\mathbf{1 . 6 ~ \mathbf { ~ m }}$ \\
\hline Width of substrate & $47.6 \mathrm{~mm}$ \\
Length of substrate & $39.8 \mathrm{~mm}$ \\
Width of the radiating patch & $37.5 \mathrm{~mm}$ \\
Length of radiating patch & $30.2 \mathrm{~mm}$ \\
Length of the feed & $4.7 \mathrm{~mm}$ \\
Width of the feed & $4.9 \mathrm{~mm}$ \\
\hline
\end{tabular}

Antenna was desinged using CST microstrip simulator software.

\section{Results and discussions}

The below graph shows the relationship between frequency and returnloss of designed antenna, Antenna is radiating at $5 \mathrm{Ghz}$ frequency and return loss is around $-35 \mathrm{~dB}$. Bandwidth $0.12 \mathrm{Ghz}$ is being observed.

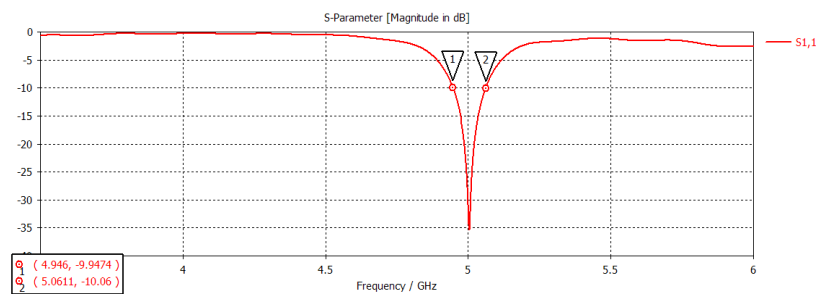

Figure 2. Return $S_{11}$ Vs Frequency.

By changing various dimension of patch the following return loss has been observed

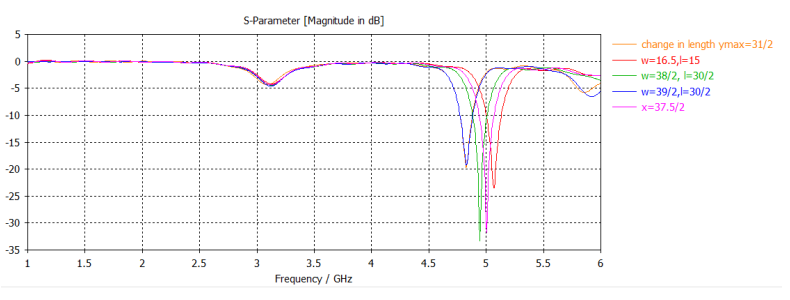

Figure 3. Return loss with various dimension variations. 
Farfield radiation pattern is shown below at $5 \mathrm{Ghz}$ frequency

$$
\text { Farfield Directivity Abs (Phi=90) }
$$

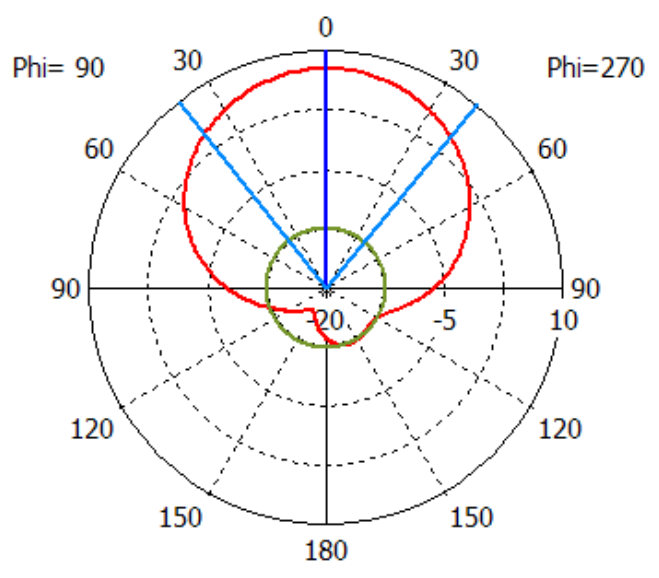

Theta / Degree vs. dBi

Figure 4. Radiation pattern at frequency $5 \mathrm{GHz}$.

Voltage standing wave graph is shown below, VSWR at $5 \mathrm{Ghz}$ frequency is very less which mean there is proper impedance matching between the source and radiating patch.

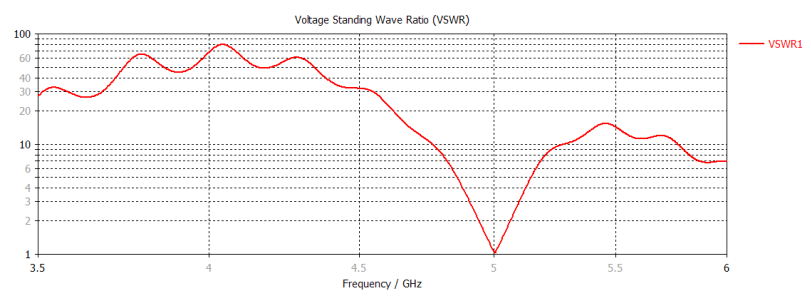

Figure 5. VSWR Vs Frequency..

\section{Conclusion}

The above antenna was designed with considerations for wearable antenna, which consists of flexible substrate material and Polystyrene is the material used as substrate which gives flexibility for folding and twisting when human bends and this can be easily worn in any human clothing. The future work of the antenna will be on learning of above found parameters while antenna is twisted and bend conditions and future work will be concentrating on bandwidth improvements.

\section{References}

1. Wong K.L. Planar Antennas for Wireless Communications. John Wiley and Sons, Inc., New Jersey; 2003.

2. Constantine. A. Balanis. Antenna Theory, Analysis and Design, John Wiley and Sons, New York; 2005.

3. Ramesh Garg, Prakash Bhartia,. Microstrip Antenna Design Handbook, Artech house, 2001.

4. Ahmad A. Sulaiman, Ahmad S. Nasaruddin. Bandwidth Enhancement in patch antenna by metamaterial substrate. European Journal of Scientific Research. 2010.

5. Massey PJ. Mobile Phone Antennas Integrated with in Clothing. in Proc. IEE 11th Int. Conf. Antennas Propag. (ICAP'01), Manchester, U.K; 2001: 1, p. 344-47.

6. Jackson DR, Long SA, Williams JT, Davis VB. ComputerAided Design of Rectangular Microstrip Antennas. ch. 5 of Advances in Microstrip and Printed Antennas, K. F. Lee, Editor, John Wiley, 1997. 